\title{
Micro-generation and Related Energy Technologies and Practices for Low Carbon Buildings
}

\author{
Guest Edited by \\ Graeme M. Burt ${ }^{\mathrm{a}}$, Evgueniy Entchev ${ }^{\mathrm{b}}$, \\ Geoffrey P. Hammond ${ }^{\mathrm{c}}$, and Nicolas J. Kelly ${ }^{\mathrm{d}}$
}

${ }^{a}$ Professor, Institute for Energy and Environment, Department of Electronic and Electrical Engineering, University of Strathclyde, 204 George Street, Glasgow. G1 1XW. UK [Email: graeme.burt@strath.ac.uk]

${ }^{\mathrm{b}}$ Head - Hybrid Energy Systems \& Advanced Energy Cycles, Integrated Energy Systems Laboratory, CanmetENERGY Research Centre, Natural Resources Canada, 1 Haanes Drive, Ottawa, Ontario. K1A-1M1.Canada [Email: Evgueniy.Entchev@NRCan-RNCan.gc.ca]

${ }^{\mathrm{c}}$ Professor, Department of Mechanical Engineering, University of Bath, Claverton Down, Bath. BA2 7AY. UK [Email: G.P.Hammond@bath.ac.uk]

${ }^{\mathrm{d}}$ Associate Director - Energy Systems Research Unit (ESRU), Department of Mechanical and Aerospace Engineering, University of Strathclyde, 141 St James Road, Glasgow. G4 0LT. UK [Email: nicolas.kelly@strath.ac.uk] 


\section{Guest Editorial}

Approximately $95 \%$ of current carbon dioxide $\left(\mathrm{CO}_{2}\right)$ emissions from the industrialised world [the so-called Annex I countries under the UN Framework Convention on Climate Change (UNFCCC)] can be attributed to the energy sector. Losses in the existing electricity supply system amount to around $65 \%$ of the primary energy input, mainly due to heat rejected from large power stations. In addition, the energy sector is operating in a context of continual change driven by a combination of environmental aspirations (particularly regarding climate change), an aging asset base, technical innovation, social trends and energy needs, government policy, and regulatory influence. Whilst this creates a high degree of uncertainty, it is widely anticipated by energy specialists that by around 2030-50 heat and power systems in the industrial world will see a significant penetration from small-scale generation, energy storage and controllable load; collectively known as 'Distributed Energy Resources' (DERs). This trend is already clearly evident in some Annex I countries, particularly Germany and the UK, where the introduction of feed-in-tariffs (FITs) stimulated exponential growth in the microgeneration market.

Micro-generation and other decentralised technologies have the potential to dramatically reduce energy sector losses because, when fossil fuels are used, the heat generated (for example) by localised electricity production can be captured and utilised for space and water heating. Heat and electricity can also be produced locally by renewable sources. Micro-generators such as micro-wind turbines and solar photovoltaic (PV) arrays are electricity-only producers, whereas heat pumps and solar hot water systems are both heat producers (mainly for space and water heating respectively). In contrast, micro-combined heat and power $(\mu \mathrm{CHP})$ devices are heat-led producers that could meet part of a household electrical demand in a flexible manner. The term 'micro-generation' can be expanded to encompass micro-'cogenerators' (including fuel cells), tri-generation systems, and renewable hybrid devices. Innovative work is required in order to research, assess and demonstrate the workings of such highly distributed energy systems that are best able to utilise these diverse DERs.

This special issue draws on a selection of papers presented at the MicroGen II - the 2nd International Conference on Micro-generation and Related Technologies - held at the University of Strathclyde in Glasgow, Scotland, UK over the period 4-6 April 2011. This was jointly sponsored by Annex 54 of the International Energy Agency (IEA) entitled 'Integration of Micro-Generation and Related Energy Technologies in Buildings' (http://www.ieaannex54.org/) and by the UK SUPERGEN 'Highly Distributed Energy Future' (HiDEF) Research Consortium (http://www.supergen-hidef.org/). The MicroGen II Conference brought together over fifty papers from sixteen different countries (including Canada, Japan, the US, and many EU states) in themes embracing developments in micro-generation and enabling technologies, practical experiences with micro-generation, integrating demand side management, integrating micro-generation within buildings, policy and planning for microgeneration, and the societal impacts of micro-generation. The HiDEF project itself seeks to identify a future UK energy system that delivers sustainability and security through the widespread deployment of DERs, thus contributing towards the attainment of a low carbon future, whilst Annex 54 of the IEA 'Energy Conservation in Buildings and Community Systems' (ECBCS) Programme is undertaking complementary in-depth analysis of microgeneration and associated energy technologies. The Annex is furthermore exploring hybrid systems that also include on site renewable generation, including small PV or micro wind generators. The nations participating in this IEA activity include Belgium, Canada, Denmark, 
Germany, Italy, Japan, Republic of Korea, the Netherlands, the UK, and the United States of America (USA).

Micro-generation and DERs can be defined as residential or small-commercial applications of the on-site generation of power with heating and/or cooling integrated into the energy management system of the building, which may include energy storage, advanced control strategies, or demand-side management. Given that centralized energy networks have been developed over many years on the premise of "many loads - few sources", novel solutions are required to support the operation and management of DERs that might be adopted on the basis of "many loads - many sources". This transition must be supported within a competitive market-oriented context and in sympathy with environmental protection. The transition from 'few' to 'many' sources being integrated with energy system operations is at an early stage, but is already influencing many aspects of grid systems, their metering, their regulation, and stakeholder relationships. This special issue reflects the interdisciplinary nature of the MicroGen II Conference, and likewise explores the possibility of decentralising five features of energy systems: resources, control, network infrastructure, participation, and policy.

The special issue commences with a paper by Darby (this issue) that addresses issues at the interface between DERs and 'participation' (end-users, markets and commercial arrangements). It outlines some practicalities of an 'active demand-side'. This implies a shift in the provision of energy away from so-called 'predict and provide' to something akin to 'predict, adapt, educate, co-provide, and store'. Load management and end-user participation in the operation of energy networks calls for more sophisticated responses to local conditions, and an infrastructure that can facilitate this, in order to assist with planning for a low-carbon energy transition. Darby's study is supported by a brief overview of the social and behavioural aspects of electricity use with examples derived from the international literature related to residential load management programmes. Four potential active demand options for a carbon-constrained electricity system are outlined in relation to customer involvement and likely enabling technologies. They include overall demand reduction, static tariffs for peak reduction, dynamic tariffs for load management with variable supply, and continuous load-balancing through dynamic demand. Each of these can offer something to the energy utilities, but Darby (this issue) argues that it is difficult to determine what these active demand options might offer the customer. They will require a number of more or less radical socio-technical changes. These are not just economic issues; she suggests that they also involve "issues of trust, daily habits and practices, familiarity with different technologies and tariffs, energy literacy, and approaches to living". Her paper consequently proposes development of a framework for evaluating 'active demand' options in terms of the benefits to the end-user. It is suggested that these users are all concerned about energy services, although the ability to control energy usage is itself valued by users.

In terms of 'resources', or individual DERs, Cooper et al. (this issue) compare and contrast air source heat pumps (ASHPs) and $\mu \mathrm{CHP}$ (or cogeneration) systems, from a perspective of thermodynamic (energy and exergy) analysis. These devices were modelled as discrete units, but within the context of the whole energy system, barring resource extraction and processing. The current mid-range ASHP and Stirling Engine (SE) $\mu$ CHP units were found to have broadly comparable performance to a condensing boiler with grid-supplied electricity for normal power-to-heat demand ratios. However, appropriately installed, state-of-art ASHP units and Solid Oxide Fuel Cell (SOFC) $\mu$ CHP units were shown to have the potential to achieve 40$50 \%$ primary energy savings. Indeed efficient SOFC- $\mu$ CHP units exhibited a higher efficiency than new centralised combined cycle gas turbine (CCGT) units; once grid losses are accounted 
for. Cooper et al. observed that the relative performance and potential of ASHP and $\mu \mathrm{CHP}$ systems is dominated by their electrical characteristics: the grid electrical generation efficiency, the power-to-heat demand ratio, and the availability of electricity for export. In cases where the total power-to-heat demand is below 1:1.5, ASHPs have greater improvement potential, because their energy efficiency is not constrained. But at higher power-to-heat ratios, $\mu \mathrm{CHP}$ units offer the potential for higher overall efficiency, and this generally occurs irrespective of whether or not the thermal energy is used effectively.

A significant increase in the electrification of domestic heating (via heat pumps or analogous devices) could result in greater peak demands on the low-voltage (LV) network that would be disproportionally higher than any rise in energy consumption. This non-dispatchable generation could pose problems for the LV network, causing fluctuations in supply voltage levels and network overloading at times of peak generation (Hong et al., this issue). These are clearly issues at the interface between 'resources' and 'network infrastructure'. In order to examine the linkage between the thermal characteristics of buildings and the scope for flexibility in ASHP operating times, a set of dynamic simulation models were developed by the authors, based on the well-regarded ESP-r building simulation platform. This interplay was assessed against the resulting impact on the comfort and convenience of the end-user. A typical UK detached dwelling and a flat were modelled in detail along with their heating system in order to determine the temporal shift achievable in ASHP operating times for present-day and future dwelling characteristics. The simulation results indicated that the scope for shifting heat pump operating times in the existing building stock was limited, with time shifts of only 1-2 hours achieved before there was a serious impact on the comfort of the occupant. But, if insulation levels were dramatically improved and substantial levels of thermal buffering were added into the heating system, Hong et al. (this issue) found that sizable time shifts of up to 6-hours were achievable without a significant impact on either space or hot water temperatures.

A field trial of another 'resource' is then reported by Lipp (this issue) from a study undertaken by Energie Südbayern (ESB), the local gas supplier in southern Bavaria (Germany). It installed four gas-fired SE $\mu \mathrm{CHP}$ units and associated measurement equipment within four different single family houses at the end of 2009. The main goals of these field tests were the analysis of the overall energy performance for the complete system. Field data evaluation shows the $\mu \mathrm{CHP}$ units work with steady-state efficiency above $90 \%$. A detailed examination of not only the space heating and the domestic hot water system demands, but also the examination of heatgenerating devices, the SE and the auxiliary burner, was made. In order to ensure the future integration of $\mu \mathrm{CHP}$ units into a smart grid, they must have predictable performance. Heat demand curves were therefore determined under both steady-state conditions and in terms of the yearly performance of each $\mu \mathrm{CHP}$ unit. Likewise, electricity generation curves at different ambient temperatures on an hourly basis were obtained. Lipp found the daily and yearly demands were quite predictable, and consequently he suggests that these DERs are suitable for use within smart grids. Lastly, the metering of feed-in power indicated that most was generated in the morning before the occupants were awake. Nevertheless, more than $90 \%$ of the generated power during the evening hours was consumed on-site.

Domestic solar hot water (SHW) systems are very common and are considered an efficient system for exploiting the renewable energy source of the sun. In Italy the national regulations require the adoption of such solar thermal 'resources' in new buildings. Water tanks are typical components for these systems, but they have a serious drawback in terms of the large amount of space needed within a building. Padovan and Manzan (this issue) report a performance study of a new water tank model featuring embedded phase change materials via the development of 
modules for the ESP-r building simulation tool. The aim of this work was to assess the possibility of using reduced-size water tanks with additional latent storage. Padovan and Manzan validate the model via test case data from the literature. A typical solar domestic hot water system has been simulated in order to study the impact of the phase change material modules inside tanks on the energy performance of the system. The results are reported using a global parameter that represents the fractional primary energy saved using the solar system. Water temperature plots with and without phase change materials have been reported as well.

A conceptual study is described by Ribberink et al. (this issue) into the hybridization of SEbased residential cogeneration $(\mu \mathrm{CHP})$ systems with solar thermal systems. They present simulated results for four hybrid system configurations applied in various locations in Canada and compared to 'base case' systems without solar input. These variants included changes in collector area, heat storage capacity, and hybrid system control strategy. Each hybrid system was simulated using the whole building simulation program TRNSYS, with annual simulations being run for various locations in Canada employing standard 'Canadian Weather for Energy Calculation' data. Ribberink et al. demonstrate that adding solar collectors to a residential cogeneration system has a clear potential to reduce natural gas consumption and greenhouse gas (GHG) emissions. The simulated cases display a 10\%-15\% decrease in the consumption of natural gas, which corresponds to a GHG emission savings of approximately 700-1200 $\mathrm{kg}$ /house-year (depending on configuration and location). In their paper, the authors highlight difficulties in optimising the performance of such hybrid systems, particularly using detailed models, due to the intrinsic complexity in the latter.

Residential solar PV generation can partially offset the electricity demand within an individual dwelling. The net demand may be readily estimated on an annual basis, but modelling its import and export with respect to time is rather more complex. This is another case of the interaction between 'resources' and 'network infrastructure'. Here domestic electricity demand, particularly for lighting, is significantly influenced by the outdoor light levels, which themselves have a direct effect on PV generation. Thus, realistic time-step simulation of the net demand requires that the two components - electricity demand and outdoor light levels - are modelled with respect to a common representation of the solar irradiance. Richardson and Thomson (this issue) present the construction of an integrated model that provides data at a one-minute time resolution, built upon a fully validated high-resolution electricity demand model. An open-source software implementation of the integrated model in 'Visual Basic for Applications' (VBA) within Microsoft Excel is described and is available for free download via the Loughborough University Institutional Repository and accessible via the HiDEF website. They found that it provides a good representation of the dynamic load curve of a whole dwelling. This may ultimately be extended to the evaluation of import/export tariffs over different time intervals.

Focusing on 'network infrastructure', the Lawrence Berkeley National Laboratory (LBNL) in California (USA) has been developing the 'Distributed Energy Resources Customer Adoption Model' (DER-CAM) for several years. DER-CAM seeks to find the optimum equipment fleet and operating schedule given load curves for energy services requirements in a building microgrid, fuel costs and other economic inputs, and a menu of available technologies. The term 'micro-grid' is used here for the control of a single building or a local grouping of buildings behind a single 'Point of Common Coupling' (PCC). Marnay et al. (this issue) show how the DER-CAM capability has been applied using the web-based 'Software as a Service' (SaaS) framework. The evolution of this approach is demonstrated via the description of four past and present projects. They all represent the interface between 'resource' and 'control' issues. The 
first of these projects was concerned with a public access website focused on solar PV generation and battery viability for large non-residential customers. This is followed by a study of potential building $\mathrm{CO}_{2}$ emissions reductions and associated investments in a dining hall at the University of California, Davis (UCD) campus, near Sacramento. The next case study involves a battery selection problem and the development of a rolling operating schedule for Santa Rita Jail; a large County correctional facility. Finally, Marnay et al. examine the direct control of the solar-assisted heating, ventilation, and air conditioning (HVAC) system of a building at the University of New Mexico (UNM), Albuquerque campus. DER-CAM was used to optimise cooling equipment scheduling at the campus Mechanical Engineering building that initially had a diverse array of thermal equipment, including solar thermal water heating, hot and chilled water storage, and a small single effect absorption chiller. It provided optimised daily schedules that could be automatically implemented within the building's energy management and control system. Marnay et al. (this issue) argue that the successful implementation of these exemplars demonstrate that optimisation of building micro-grid design and operation can be effectively achieved using the SaaS tool.

Micro-generation must become an important part of the overall 'network infrastructure' reinforcement and replacement strategy. Novel techniques for the evaluation of alternative strategies for network and generation infrastructure development are required that include distributed generation at a national level. This is a poorly researched topic in terms of system support and ancillary services. Pudjianto and Strbac (this issue) have investigated the use of a multi-state 'Optimal Power Flow' (OPF) algorithm that simultaneously optimises the capacity utilisation of micro-generators to produce electricity in combination with the provision of spinning/standing reserve. The optimisation was undertaken using various market datasets, including energy and reserve markets, operating cost and technical characteristics of DERs, network constraints to optimise the dispatch and allocation of reserves. Two operating states were considered for 'control' of the network: one base case where the scheduled reserve is not utilised and another state where all scheduled reserve was utilised. The OPF algorithm ensured that in both states, the system could be operated securely and that no network operating limits/constraints were violated. Pudjianto and Strbac demonstrate the feasibility of the proposed OPF algorithm through a number of case studies on a LV network. The studies demonstrate that micro-generators are capable of contributing to both local and system support services, particularly in the forms of reserve and voltage control. They can simultaneously optimise the portfolio of energy production in order to maximise the benefits for the owners of micro-generators and improve the efficiency of the overall system.

The future of the energy supply 'network infrastructure' in the UK suggests ambitions for achieving a sustainable and reliable energy network, which could potentially be realised through decentralised and flexible 'participation'. Such a highly distributed energy system might be expected to deliver these objectives through the widespread use of DERs, thereby contributing to the national aim of a low carbon future by 2050. Existing research in the area of DER integration has developed a methodology, known as 'Energy Hubs', to formally model heterogeneous energy flows within a network. They are able to harness generation from multiple energy carriers, allowing a modular energy network construction that facilitates system optimisation through the placement of DERs within each hub. Anderson et al. (this issue) present the Energy Hub approach to modelling a decentralised energy network. This involved detailed modelling of local energy networks with multiple energy carriers in novel analyses of generation and demand. Multiple DERs were modelled in isolation, as part of a discrete system, in order to then solve an economic dispatch problem at a regional level using the Energy Hub concept. This approach has been illustrated with two case studies from the east 
and west coasts of Scotland. The resulting analysis illustrates the impact of differing energy mixes (e.g., the proportions of $\mu \mathrm{CHP}$, solar PV panels, and micro-wind turbines) available, whilst reflecting the subtle differences in demands across areas with different weather profiles. Anderson et al. argues that modelling of this type is likely to be pivotal in the planning of future networks in such a way as to ensure they function optimally and also in directing policy towards encouraging consumers to adopt a different, more decentralised approach to energy generation.

Hydrogen $\left(\mathrm{H}_{2}\right)$ could become an important energy carrier in future energy systems and be used as an input to fuel cell electric vehicles as part of the electrification of transport. Alkaline electrolysers are an attractive technology to produce carbon-free $\mathrm{H}_{2}$ from renewable-generated electricity. The large-scale deployment of alkaline electrolysers used in future $\mathrm{H}_{2}$ filling stations could also be utilised to support the frequency stability of future grids, particularly valuable in those containing a high proportion of renewable generation. The electrolyser load can be controlled to respond to power system frequency variations, and in the case of a sudden loss of generation, these electrolysers could rapidly decrease their load on the system to restore power balance, i.e., in less than 200 milliseconds. Kiaee et al. (this issue) have therefore examined the potential of alkaline electrolysers to dynamically stabilise the frequency of the power system as a 'network infrastructure' issue. A simplified model of a steam turbine generation unit was developed in the MATLAB SIMULINK environment, and a scenario explored in which there is a sudden loss of generation in the system. Kiaee et al. demonstrate that alkaline electrolysers could prevent unacceptable frequency drop (i.e., below typical statutory limits) following an abrupt loss of generation, even with no spinning reserve on the system. They determined, using experimental data, the ramping rate required of a pressurised alkaline electrolyser.

Finally, Bergman (this issue) returns to a socio-technical issue, but one that is more focused on the 'policy' domain. He notes that some recent studies on solar hot water heating (SHW) and heat pumps suggest that few micro-generation installations are delivering the expected energy or emissions savings, and that consumers are, in turn, not securing the expected financial benefits. The reasons are a mixture of technical problems and poor installations, institutional issues, poor information supply to users, and improper use. Bergman considers that such issues could delay or jeopardise plans for rolling out micro-generators, such as heat pumps. He advocates policies which would help to maximise the benefits of micro-generation, including the implications for the 'Renewable Heat Incentive' (RHI) in the UK. In his view, a broader systemic approach must be used, with concepts from 'transitions' theory and 'strategic niche management' being used to analyse the institutional, cultural and behavioural reasons for their relatively poor performance. Thus, building up the niche heat pump market will necessitate new skills and changed attitudes in the industry. The technical and cultural differences between metering of gas/heat and electricity might also have inhibited heat pump performance. Bergman (this issue) suggests that RHI calculations must rely on measuring systems in use in real homes, not just on laboratory tests and modelling predictions. There may obviously be other low or zero carbon alternatives to heat pumps going forward, including biomass-heat.

In summary, this special issue considers the technical capability of various DERs (such as solar hot water systems, heat pumps, $\mu \mathrm{CHP}$ plants, and solar PV arrays) to provide energy services, alongside the cost, complexity and wider implications of the different options. It therefore collectively explores the possibility of decentralising energy systems in the context of five important features: resources, control, network infrastructure, participation, and policy. The papers published here have addressed areas that have included the effective incorporation of DERs into (mainly individual) buildings, their augmentation by way of energy storage and 
demand side management, and the analysis of their wider impact on power networks. Architectures suited to a highly distributed energy future will clearly be required to put endusers at the heart of system operation, provide effective technical and market integration of all end-use technologies within the network, and provide the accessibility and flexibility to incorporate future technological innovations. The special issue has therefore attempted to highlight barriers to critical technical capabilities and to market developments. The Guest Editors believe that this discourse may be able to influence the ongoing, nearer-term development of energy policy in key countries within the industrialized world. Developing countries and emerging economies (such as China and India) are also interested in the development of DERs and their associated infrastructural requirements, but rather more from a perspective of enhancing energy security (limiting 'blackouts') than of climate change mitigation. The valuable contribution of the authors to both the lively debate at MicroGen II and to the developed papers in this special issue is warmly acknowledged.

G.M. Burt, E. Entchev, G.P. Hammond, and N.J. Kelly, December 2012
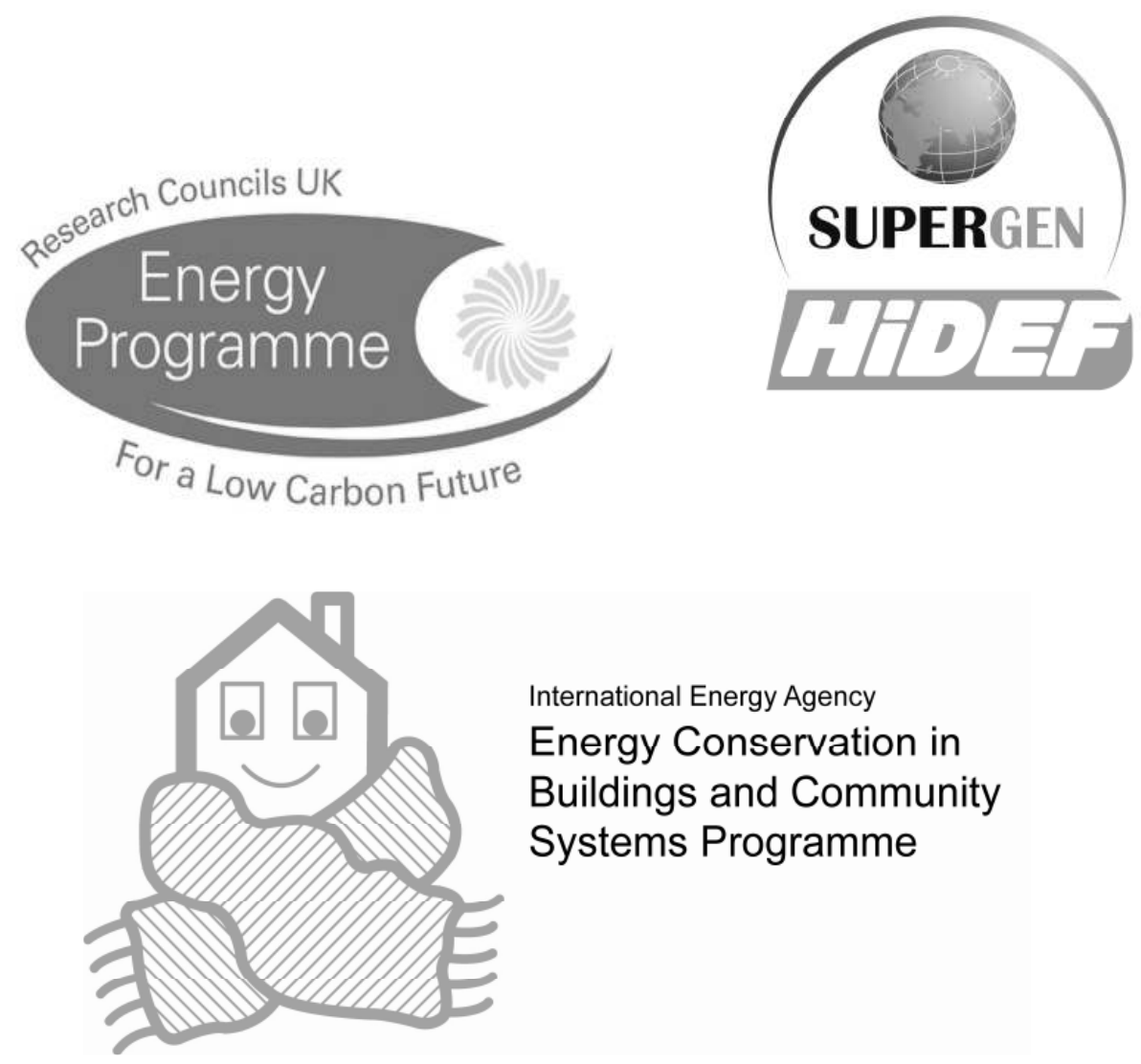

International Energy Agency

Energy Conservation in

Buildings and Community

Systems Programme 


\section{Contents/Running Order}

Guest Editorial: 'Micro-generation and Related Energy Technologies and Practices for Low Carbon Buildings'

Darby, 'Load management at home: Advantages and drawbacks of some 'active demand side' options' (JPE1500)

Cooper et al., 'Thermodynamic efficiency of low-carbon domestic heating systems: heat pumps and micro-cogeneration' (JPE1480)

Hong et al., 'Assessing heat pumps as flexible load' (JPE1481)

Lipp, 'Field test within Stirling engine micro-CHP units in residential buildings' (JPE1482)

Padovan and Manzan, 'Development of a stratified tank storage component for ESP-r with embedded phase change material modules' (JPE1498)

Ribberink et al., 'Investigation of a hybrid renewable-microgeneration energy system for power and thermal generation with reduced emissions' (JPE1483)

Richardson and Thomson, 'Integrated simulation of photovoltaic micro-generation and domestic electricity demand: a one-minute resolution open-source model' (JPE1494)

Marnay et al., 'Application of optimal building energy system selection and operation' (JPE1507)

Pudjianto and Strbac, 'Maximizing the utilisation of micro-generation using a multistate optimal power flow' (JPE1484)

Anderson et al., 'Assessment of the impact of different energy mixes in local decentralised energy networks' (JPE1501)

Kiaee et al., 'Improvement of power system frequency stability using alkaline electrolysis plants' (JPE1485)

Bergman, 'Why is renewable heat in the UK underperforming? A socio-technical perspective' (JPE1495) 